\title{
JIMI
}

\section{Dampak Perubahan Harga Minyak Dunia, Nilai Tukar dan Inflasi terhadap Neraca Perdagangan di Negara-Negara Islam}

\author{
Hamimah $^{\mathrm{al}}$ \\ ${ }^{1}$ Prodi Ekonomi Islam, Fakultas Ekonomi dan Bisnis, Untan, INDONESIA, email: \\ hamimahendut123@gmail.com
}

\begin{abstract}
ABSTRAK
Penelitian ini bertujuan untuk mempelajari dan menganalisis dampak perubahan harga minyak dunia, nilai tukar, dan inflasi terhadap neraca perdagangan pada empat negara Islam yaitu Malaysia, Brunei Darussalam, Saudi Arabia, dan Indonesia. Metode pada penelitian ini adalah uji regresi data panel dengan periode pengamatan dalam kurun waktu 16 tahun, (2001-2017). Berdasarkan hasil uji, penelitian ini menunjukkan harga minyak dan inflasi memiliki pengaruh positif dan signifikan terhadap neraca perdagangan, sedangkan nilai tukar memiliki pengaruh negatif dan tidak signifikan terhadap neraca perdagangan pada empat negara Islam yaitu Malaysia, Brunei Darussalam, Saudi Arabia, dan Indonesia.
\end{abstract}

Kata Kunci: Harga Minyak, Nilai Tukar, Inflasi, Neraca Perdagangan 


\section{PENDAHULUAN}

Dalam pandangan Islam, perdagangan (perniagaan) memiliki kedudukan yang tinggi. Orang-orang yang jujur dalam perdagangan disamakan dengan para syuhada. Perdagangan bukan maksud, tetapi hanya tujuan untuk mendukung dan memudahkan dalam beramal soleh. Dengan perdagangan memungkinkan barangbarang dan jasa diperjual belikan untuk memenuhi kebutuhan umat manusia di muka bumi. Allah menganjurkan untuk memanfaatkan nikmat-nikmat material yang ada di bumi sebagaimana tercantum dalam penggalan QS. Al-Baqarah ayat 198, yang artinya: "tidak ada dosa bagimu mencari karunia (rezeki hasil perniagaan) dari Rabb-mu."

Ayat ini diturunkan sehubungan dengan keragu-raguan orang Islam pada permulaan datangnya Islam untuk berusaha mencari rezeki, sehingga banyak di antara mereka yang menutup toko-toko mereka pada waktu musim haji, karena takut berdosa. Diriwayatkan oleh al-Bukhari dari Ibnu 'Abbas, dia berkata "pada zaman jahiliyah ada 3 pasar, yaitu Ukaz, Majannah, dan Zulmajaz." Pada waktu musim haji, kaum Muslimin merasa berdosa berdagang di pasar-pasar itu, lalu mereka bertanya kepada Rasulullah SAW, maka turunlah ayat ini. Berusaha mencari rezeki yang halal selama mengerjakan haji adalah dibolehkan selama usaha itu dilakukan secara sambilan, bukan menjadi tujuan. Tujuan utama ialah mengerjakan ibadah haji dengan penuh takwa kepada Allah dan dengan hati yang tulus ikhlas.

Menurut Ackerman (2005) keuntungan dari perdagangan internasional (gains from trade)-memberi peluang setiap negara untuk mengekspor dan mengimport barang-barang dan jasa yang diproduksi dengan menggunakan sumber daya alam yang mereka miliki. Negara dengan perdagangan yang kuat akan mendorong kesejehteraan negaranya. Perdagangan internasional memungkinkan level ekonomi antar negara akan semakin meningkat dan terbuka sehingga membuat transaksi perdagangan makin mudah dan murah.

Neraca perdagangan adalah selisih antara kegiatan ekspor dan import suatu negara dengan negara lainnya secara internasional (Hendarmin dan Kartika, 2019). Jika eksportnya lebih banyak dari import maka negara itu mengalam surplus perdagangan, demikian sebaliknya. Keseimbangan negara pembayaran tergantung pada faktor seperti inflasi, nilai tukar dan perubahan harga minyak dunia. Pengaruh inflasi ke neraca perdagangan, jika inflasi satu negara naik maka Neraca perdagangan akan mengalami defisit kerena harga dalam negeri meningkat. Harga minyak dunia yang tinggi juga dapat berpengaruh kepada neraca pembayaran melui mekanisme stok barang yang terjual. Jika harga naik maka import akan berkurang dan dapat mengganggu neraca pembayaran. Dalam janga pendek kenaiakan harga manyak dunia dapat mendorong perdagangan, namun itu tidak bisa berlangsung lama. Nilai tular suatu negara akan mepengaruhi neraca pembayaran. Jika nilai tukar meningkat (apresiasi) maka neraca perdagangan akan menurun, demikian sebaliknya jika terjadi depresiasi, syprlus neraca perdagangan akan meningkat.

Perubahan harga minyak dunia, nilai tukar, dan inflasi terhadap neraca perdagangan di setiap negara mengalami perubahan yang berbeda bergantung pada kebijakan serta sistem pemerintah yang dianut oleh suatu negara (Agustiar, 2020). Negara Malaysia, Brunei Darussalam, Saudi Arabia, dan Indonesia yang memiliki sistem pemerintahan berbeda, hal ini menjadi menarik untuk dilakukan analisis yang terjadi apabila harga minyak dunia, nilai tukar, dan inflasi mengalami 
perubahan terhadap neraca perdagangan masing-masing negara: Tujuan penelitian (1) untuk mengetahui dan menganalisis dampak perubahan harga minyak dunia terhadap neraca perdagangan di 4 negara Islam (Malaysia, Brunei Darussalam, Saudi Arabia, dan Indonesia), (2) untuk mengetahui pengaruh perubahan nilai tukar terhadap neraca perdagangan di 4 negara Islam dan (3) untuk mengetahui pengaruh perubahan inflasi terhadap neraca perdagangan di 4 negara Islam Hasil penelitian akan menambah pengetahuan serta sumbangsih dalam bidang ekonomi dan Islam khususnya pada aspek perdagangan internasional.

\section{LANDASAN TEORI}

Teori klasik menyatakan keuntungan mutlak yang didapat oleh suatu negara karena berhasil menekan biaya produksi barang dengan yang lebih rendah dibanding negara lain. Di dalam islam perdagangan internasional menjadi salah satu masalah muamalah dan maqashid bagi kemaslahatan manusia jika sesuai yang disyariatkan. Potret pertama yang ditulis dalam Alquran adalah perdagangan kaum Qurauisy pada masa Nabi Muhammad SAW membawa dagangan milik istri Nabi yaitu Siti Khadijah, perdagangan dilakukan hingga ke Negeri Syam. Dalam QS. Al Quraisy ayat 2 sebagai berikut:Artinya: "(yaitu) kebiasaan mereka bepergian pada musim dingin dan musim panas".

Teori Harga mengatakan bahwa harga ditentukan oleh bertemunya dua kekuatan atau pengaruh yaitu permintaan dan penawaran (Rosyidi, 2017). Kurs atau nilai tukar suatu mata uang adalah nilai tukar mata uang suatu negara terhadap negara asing lainnya (Thobarry, 2009). Aktivitas pertukaran mata uang yang terjadi dalam islam disebut sharf. Al-Sharf merupakan jual beli atau pertukaran antara satu mata uang lain seperti rupiah dengan dolar, dolar dan mata uang lainnya (Arifin, 2003). Dalam hal ini QS. Al-Kahfi ayat 19 menjelaskan:

Artinya: 'Dan demikianlah Kami bangunkan mereka agar mereka saling bertanya di antara mereka sendiri. Berkatalah salah seorang di antara mereka: Sudah berapa lamakah kamu berada (disini?)". Mereka menjawab: "Kita berada (disini) sehari atau setengah hari". Berkata (yang lain lagi): "Tuhan kamu lebih mengetahui berapa lamanya kamu berada (di sini). Maka suruhlah salah seorang di antara kamu untuk pergi ke kota dengan membawa uang perakmu ini, dan hendaklah dia lihat manakah makanan yang lebih baik, maka hendaklah ia membawa makanan itu untukmu, dan hendaklah ia berlaku lemah-lembut dan janganlah sekali-kali menceritakan halmu kepada seorangpun".

Menurut Raharjha dan Marunung (2008) inflasi adalah gejala kenaikan harga barang-barang yang bersifat umum dan terus menerus, dengan beberapa anggapan bahwa telah terjadi inflasi yaitu kenaikan harga, terus menerus dan bersifat umum. Dalam islam tidak mengenal istilah inflasi dikarenakan islam memiliki mata uang yang stabil yaitu dinar dirham. Namun inflasi pernah terjadi pertama kali pada masa Rasulullah dan Khulafaur Rasyidin yaitu kekeringan atau peperangan.

Al-Maqrizi (1364M- 1441M) dalam bukunya Amelia (2005) juga mengatakan bahwa inflasi kedua terjadi karena tiga hal yang di lakukan oleh manusia sendiri sesuai dengan QS. Ar-Rum ayat 41: Artinya: "Telah tampak kerusakan di darat dan di laut di sebabkan karena tangan manusia, supaya Allah merasakan kepada mereka sebagian dari (akibat) perbuatan mereka, agar mereka kembali (ke jalan yang benar)". 


\section{METODE PENELITIAN}

Penelitian ini menggunakan pendekatan kuantitatif (analisis regresi) dengan data panel dalam kurun waktu 16 tahun (2001-2017), observasi dilakukan terhadap empat negara Islam yaitu: Malaysia, Brunei Darussalam, Saudi Arabia, dan Indonesia. Variabel yang digunakan harga minyak dunia, nilai tukar, inflasi dan neraca perdagangan.

\section{Analisis Regresi Data Panel}

Regresi dengan data bentuk gabungan antara unsur runtut ruang dan runtut waktu. Adapun model regresi panel pada penelitian ini adalah random effect model dengan persamaan sebagai berikut:

Keterangan:

$$
\mathrm{TB}_{\mathrm{it}}=\alpha+\beta_{1} \mathrm{PO}_{\mathrm{it}}+\beta_{2} \mathrm{ER}_{\mathrm{it}}+\beta_{3} \mathrm{INF}_{\mathrm{it}}+\mathrm{e}_{\mathrm{it}}
$$

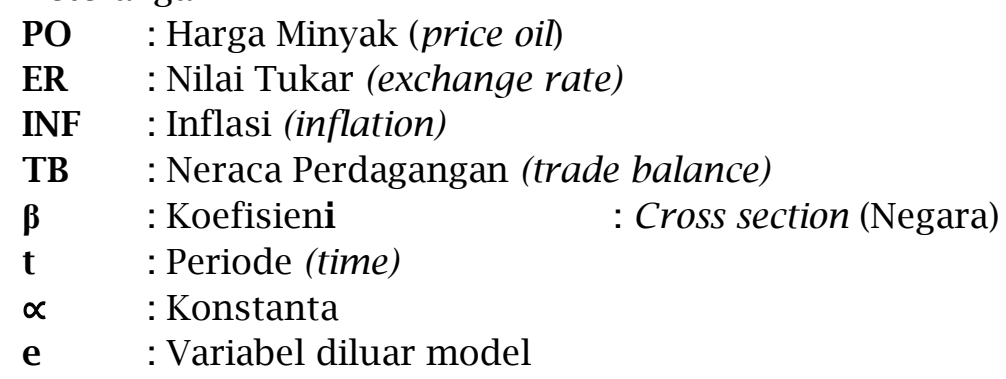

\section{HASIL DAN PEMBAHASAN}

Berdasarkan hasil pemilihan model di atas, random effect model lebih baik dalam menjelaskan model regresi data panel dalam penelitian ini. Berikut hasil estimasi random effect model.

Tabel 1: Hasil Uji Regresi Data Panel (Random Effect Model)

\begin{tabular}{crrrl}
\hline Variabel & Koefisien & Std. Error & t-Statistic & Prob. \\
\hline C & -6.050169 & 22.33616 & -0.270869 & 0.7874 \\
LOGPO & 0.530096 & 0.134832 & 3.931524 & 0.0002 \\
LOGER & -0.002635 & 0.002799 & -0.941674 & 0.3499 \\
INF & 3.707887 & 1.725838 & 2.148455 & 0.0355
\end{tabular}

\section{Random Effect (Cross)}

Malaysia

Brunei Darussalam

Saudi Arabia

Indonesia

Sumber: Hasil Pengolahan Uji EViews 10 (Data diolah, 2020)

$$
\begin{array}{cccc}
\text { LOGTB }_{\text {it }}=-6.050169+0.530096 \mathrm{LOGPO}_{\text {it }}-0.002635 \mathrm{LOGER}_{\mathrm{it}}+3.707887 \mathrm{INF}_{\text {it }} \mathrm{E}_{\mathrm{it}} \\
\text { Prob.t-stat }= & (0.0002) & (0.3499) & (0.0355)
\end{array}
$$

$$
\mathrm{R}^{2}=0.274834
$$

Hasil regresi tersebut dapat dijelaskan melalui hasil interpretasi koefisien/konstanta dan interpretasi data variabel independen terhadap variabel dependen adalah sebagai berikut:

1) Interpretasi koefisien atau konstanta

a) Brunei Darussalam: $-0.60+(-24.03)=-24.63$ 
Jika variabel independen yaitu harga minyak dunia (PO), nilai tukar (ER), dan Inflasi (INF) konstan, maka neraca perdagangan di Negara Brunei Darussalam mengalami penurunan sebesar $24.63 \%$

b) Indonesia: $-0.60+(-15.09)=-15.69$

Jika variabel independen yaitu harga minyak dunia (PO), nilai tukar (ER), dan Inflasi (INF) konstan, maka neraca perdagangan di Negara Indonesia mengalami penurunan sebesar $15.69 \%$

c) Malaysia: $-0.60+(-5.17)=-5.77$

Jika variabel independen yaitu harga minyak dunia (PO), nilai tukar (ER), dan Inflasi (INF) konstan, maka neraca perdagangan di Negara Malaysia mengalami penurunan sebesar $5.77 \%$

d) Saudi Arabia: $-0.60+44.29=43.69$

Jika variabel independen yaitu harga minyak dunia (PO), nilai tukar (ER), dan Inflasi (INF) konstan, maka neraca perdagangan di Negara Saudi Arabia mengalami kenaikan sebesar 43.69\%

2) Interpretasi Data variabel independen terhadap variabel dependen

a) Jika harga minyak (PO) mengalami peningkatan sebesar 1\%, maka neraca perdagangan akan mengalami kenaikan sebesar $0.53 \%$.

b) Jika nilai tukar (ER) mengalami peningkatan sebesar 1\%, maka neraca perdagangan akan mengalami penurunan sebesar 0.002\%.

c) Jika inflasi (INF) mengalami peningkatan sebesar 1\%, maka neraca perdagangan akan mengalami kenaikan sebesar 3.70\%.

Selanjutnya dapat dilakukan analisis secara bersamaan di setiap negara seperti terlihat pada tabel 1, dampak perubahan harga minyak dunia terhadap neraca perdagangan di negara Islam yaitu Malaysia, Brunei Darussalam, Saudi Arabia, dan Indonesia mengacu pada penelitian Obadi, dkk. (2017) dalam penelitiannya bahwa harga minyak mentah dunia berdampak positif dan signifikan terhadap neraca perdagangan bagi negara pengimpor, sebaliknya harga minyak berdampak negatif bagi negara pengekspor minyak.

Kemudian analisis secara bersamaan negara seperti terlihat pada tabel 1 , dampak perubahan nilai tukar terhadap neraca perdagangan di negara Islam yaitu Malaysia, Brunei Darussalam, Saudi Arabia, dan Indonesia. Penelitian Bartolini dan Bodnar (1996), yang mengatakan bahwa tidak ditemukan secara signifikan volatilitas/cenderung berubah-ubah yang bersifat excessive yang menggunakan sudut pandang moneter menunjukkan bahwa volatilitas yang terjadi pada nilai tukar cenderung untuk berjalan normal. Nilai tukar juga tidak mempengaruhi neraca pendapatan (neraca perdagangan) di lima Negara OECD (Organization for Economic Co-operation and Development) pasca Era Bretton Woods.

Analisis selanjutnya terlihat pada tabel 1, dampak perubahan inflasi terhadap neraca perdagangan di negara Islam yaitu Malaysia, Brunei Darussalam, Saudi Arabia, dan Indonesia. Penelitian Kusuma dan Hakim (2012) mengatakan bahwa dalam jangka panjang, PDB, kurs, dan inflasi mempengaruhi fluktuasi neraca perdagangan Indonesia. Dalam jangka pendek ditemukan variabel PDB dan inflasi yang secara signifikan mempengaruhi neraca perdagangan Indonesia. Secara simultan inflasi dan kurs signifikan terhadap ekspor-impor. Inflasi, kurs dan ekspor-impor secara simultan signifikan terhadap neraca perdagangan (Udiyana dan Setiyarti, 2017). 


\section{KESIMPULAN}

Penelitian ini bertujuan mempelajari dan menganalisis dampak perubahan harga minyak dunia, nilai tukar dan inflasi terhadap neraca perdagangan di negara islam yaitu Malaysia, Brunei Darussalam, Saudi Arabia dan Indonesia. Hasilnya menunjukan bahwa dampak perubahan harga minyak dunia terhadap neraca perdagangan memiliki hubungan yang positif. Hal ini menunjukkan perubahan naik turunnya harga minyak dunia mempengaruhi neraca perdagangan. Dampak perubahan nilai tukar terhadap neraca perdagangan menunjukkan nilai tukar tidak signifikan. Dampak perubahan inflasi terhadap neraca perdagangan menunjukkan hasil uji $\mathrm{t}$ positif dan signifikan. Penelitian ini menggunakan tiga variabel independen yaitu harga minyak dunia, nilai tukar dan inflasi memiliki hasil RSquare $0.27 \%$ sehingga kurang mampu menjelaskan variabel dependen neraca perdagangan dikarenakan masih banyak faktor lain yang mempengaruhinya, namun peneliti telah maksimal membangun penjelasan untuk melihat perubahan yang terjadi antar variabel penelitian.

\section{DAFTAR PUSTAKA}

Ackerman, F. (2005). The shrinking gains from trade: a critical assessment of Doha Round projections (No. 1434-2016-118837).

Agustiar, M. (2020). Monetary integration among oil exporter countries: Testing Kenen's product diversification hypothesis in the organization of Islamic cooperation. International Journal of Energy Economics and Policy, 10(3), 380.

Amelia, E. (2005). Sejarah Pemikiran Islam dari Masa klasik hingga Kontenporer . Jakarta: Pustaka Asatrus.Arifin, Z. (2003). Dasar-Dasar Manajemen Bank Syariah . cet II Jakarta: Alvabet.

Bartolini, L., \& Bodnar, G. M. (1996). Are exchange rates excessively volatile? And what does "excessively volatile" mean, anyway?. Staff Papers, 43(1), 72-96.

Hendarmin, H., \& Kartika, M. (2019). The relationship between human capital and the regional economy productivity. JEJAK: Jurnal Ekonomi dan Kebijakan, 12(1), 138-152.

Kementerian Agama, R. I. (2012). Al-Qur'an dan Terjemahannya, Jakarta: PT. Sinergi Pustaka Indonesia.

Kusuma, R. I., \& Hakim, A. (2012). Kajian Empiris Fluktuasi Neraca Perdagangan Indonesia. UNISIA, 34(77), 135-148.

Obadi, S. M., Kosir, I., \& Korcek, M. (2017). The impact of low oil prices on the trade balance of Balkan countries and their energy security. Energy Economics Letters, 4(3), 20-27.

Rahardja, P., \& Manurung, M. (2008). Teori Ekonomi Makro. Jakarta: LPFEUI.

Rosyidi, S. (2006). Pengantar Teori Ekonomi Pendekatan Kepada Teori Ekonomi Mikro \& Makro. Jakarta: Rajawali Pers.

Thobarry, A. A. (2009). Analisis pengaruh nilai tukar, suku bunga, laju inflasi dan pertumbuhan GDP terhadap indeks harga saham sektor properti (kajian empiris pada Bursa Efek Indonesia periode pengamatan tahun 20002008) (Doctoral dissertation, Program Pasca Sarjana Universitas Diponegoro).

Udiyana, I. B. G., \& Setiyarti, T. (2017, January). Fluktuasi Nilai Kurs dan Inflasi Pengaruhnya Terhadap Ekspor Impor dan Neraca Perdagangan Indonesia 
Tahun 2007-2015. In Forum Manajemen STIMI Handayani Denpasar (Vol. 15, No. 1, pp. 76-86). 